\title{
Development of Ecoefficient Engineered Cementitious Composites Using Supplementary Cementitious Materials as a Binder and Bottom Ash Aggregate as Fine Aggregate
}

\author{
Jin Wook Bang, ${ }^{1}$ G. Ganesh Prabhu, ${ }^{2}$ Yong Il Jang, ${ }^{3}$ and Yun Yong Kim ${ }^{1}$ \\ ${ }^{1}$ Department of Civil Engineering, Chungnam National University, Daejeon 305-764, Republic of Korea \\ ${ }^{2}$ Department of Civil Engineering, KPR Institute of Engineering and Technology, Coimbatore, Tamil Nadu 641 407, India \\ ${ }^{3}$ Department of Construction Engineering Education, Chungnam National University, Daejeon 305-764, Republic of Korea \\ Correspondence should be addressed to Yun Yong Kim; yunkim@cnu.ac.kr
}

Received 14 February 2015; Revised 23 March 2015; Accepted 27 March 2015

Academic Editor: Togay Ozbakkaloglu

Copyright (C) 2015 Jin Wook Bang et al. This is an open access article distributed under the Creative Commons Attribution License, which permits unrestricted use, distribution, and reproduction in any medium, provided the original work is properly cited.

\begin{abstract}
The purpose of this study is to develop ecoefficient engineered cementitious composites (ECC) using supplementary cementitious materials (SCMs), including fly ash (FA) and blast furnace slag (SL) as a binder material. The cement content of the ECC mixtures was replaced by FA and SL with a replacement rate of $25 \%$. In addition, the fine aggregate of the ECC was replaced by bottom ash aggregate (BA) with a substitution rate of $10 \%, 20 \%$, and $30 \%$. The influences of ecofriendly aggregates on fresh concrete properties and on mechanical properties were experimentally investigated. The test results revealed that the substitution of SCMs has an advantageous effect on fresh concrete's properties; however, the increased water absorption and the irregular shape of the BA can potentially affect the fresh concrete's properties. The substitution of FA and SL in ECC led to an increase in frictional bond at the interface between PVA fibers and matrix, improved the fiber dispersion, and showed a tensile strain capacity ranging from $3.3 \%$ to $3.5 \%$. It is suggested that the combination of SCMs (12.5\% FA and $12.5 \% \mathrm{SL})$ and the BA aggregate with the substitution rate of $10 \%$ can be effectively used in ECC preparation.
\end{abstract}

\section{Introduction}

Engineered cementitious composites (ECC) are a special generation of high performance fiber reinforced cementitious composites (HPFRCC), which are characterized by pseudo strain-hardening behavior and tight crack width $[1,2]$. The micromechanical design of ECC exhibits a remarkable tensile ductility capacity, even though the ECC includes short fibers in a volume fraction of around $2 \%$. The strain-hardening behavior of ECC is very similar to the ductile metal and exhibits a strain capacity 500-600 times higher than that of normal concrete [3]. The aggregates in ECC significantly influence the strain-hardening performance through alterations in matrix fracture toughness and fiber dispersion; furthermore, in order to attain the remarkable tensile performance and avoid fiber clumping, the use of coarse aggregate has been avoided in the standard ECC mixture [1]. The fiber dispersion in ECC is the highly important property and has led to a reduction in the number of effective fibers at the failure crack phase, causing decline in tensile capacity. Therefore, microsilica sand (SS) with an average size of $110 \mu \mathrm{m}$ is used in ECC mixture, to maintain uniform fiber dispersion and low fracture toughness.

The use of cement content in the ECC is nearly 5 times higher than that in normal concrete, resulting in higher shrinkage, heat of hydration, and cost [3]. The increased utilization of ECC led to increased $\mathrm{CO}_{2}$ emissions, significantly contributing to pollution health risks and global warming. Over the past several decades, the inclusion/replacement of cement using supplementary cementitious materials (SCMs) including silica fume, fly ash (FA), and granulated blast furnace slag (SL) in concrete has improved the engineering properties of the concrete. Among these SCMs, FA and SL have been widely used as successful replacement materials for cement [4-6] and in particular FA has been successfully used in concrete production around the world for over 50 years [7]. 
TABLE 1: Chemical composition of cement, SCMs, SS, and BA.

\begin{tabular}{|c|c|c|c|c|c|}
\hline Chemical composition & $\begin{array}{l}\text { OPC } \\
(\%)\end{array}$ & $\begin{array}{c}\text { Fly ash (FA) } \\
(\%)\end{array}$ & $\begin{array}{l}\text { Blast furnace slag (SL) } \\
\qquad(\%)\end{array}$ & $\begin{array}{c}\text { Silica sand (SS) } \\
(\%)\end{array}$ & $\begin{array}{c}\text { Bottom ash aggregate (BA) } \\
(\%)\end{array}$ \\
\hline Lime (as $\mathrm{CaO}$ ) & 62.80 & 3.61 & 45.95 & - & 2.48 \\
\hline Soluble silica (as $\mathrm{SiO}_{2}$ ) & 21.16 & 50.72 & 28.14 & 98.10 & 47.90 \\
\hline Alumina $\left(\right.$ as $\mathrm{Al}_{2} \mathrm{O}_{3}$ ) & 4.65 & 20.73 & 15.87 & 1.12 & 25.94 \\
\hline Iron oxide (as $\mathrm{Fe}_{2} \mathrm{O}_{3}$ ) & 3.14 & 6.37 & 1.06 & 0.71 & 4.76 \\
\hline Magnesia (as MgO) & 2.18 & 1.08 & 4.98 & - & 1.10 \\
\hline $\begin{array}{l}\text { Sulphur calculated as } \\
\text { sulphuric anhydride (as } \\
\mathrm{SO}_{3} \text { ) }\end{array}$ & 2.13 & 0.54 & 2.12 & - & - \\
\hline Loss on ignition (LOI) & 2.18 & 3.04 & 0.35 & - & - \\
\hline $\mathrm{Na}_{2} \mathrm{O}$ & - & - & - & - & 1.38 \\
\hline
\end{tabular}

In addition, it has been recognized that the SL with a vitreous microstructure has not only a filler but also a dispersing effect associated with the surface chemical action [8]. In recent years, the development of ecoefficient ECC using SCMs, specifically using FA and SL, has become widespread $[9,10]$ with the goal of reducing environmental impacts. The increase in FA content in ECC reduces the matrix toughness and increases the interface frictional bond, enhancing the tensile strain capacity as a result [11]. Furthermore, the ECC mixtures with high volumes of FA remain durable in terms of mechanical performance after an accelerated aging period and show a tensile strain capacity of more than 2\% [7]. The dosage of SL in ECC controlled the multiple cracking and also enhanced the fiber/matrix bond strength $[2,10]$.

Even though there has been some research regarding the influence of SCMs (particularly FA and SL) on the engineering properties of ECC, more research is needed to understand the effects of an FA and SL combination (binary SCMs) on the engineering properties of ECC. In addition, the manufacturing of the SS used in standard ECC is quite expensive, and the $\mathrm{CO}_{2}$ emissions associated with the manufacture of SS are known to create environmental problems [1]. For this reason, it has become imperative to find an alternative ecofriendly fine aggregate. Coal has been significantly used as a fuel in electricity production in Korea, and more than 6 million tons of coal has been utilized annually for the same. When coal is burned in a boiler for power generation, three types of by-products including FA, bottom ash (BA), and boiler slag are produced. FA has proved to be a valuable SCM in many applications, especially cement manufacturing. However, BA, which is removed from the bottom of the furnace, has not been reutilized effectively compared to FA. The formation of BA is about $10-15 \%$ of the total amount of coal utilized, meaning millions of tons of waste. In Korea, most BA is buried in the soil, which creates an environmental problem and soil contamination. As such, it is necessary to find ways to reuse BA in order to achieve sustainable development.

To resolve these issues, an investigation was carried out to develop an ecoefficient ECC using SCMs including $\mathrm{FA}$ and SL as a binder and BA as a fine aggregate. The cement content of the ECC mixtures is replaced by FA and
SL as a binary binder system (cement + FA and cement + SL) and ternary binder system (cement + FA + SL). Huang et al. [1] and Şahmaran and Li [7] found that the increase in the substitution of FA slightly improves the strainhardening capacity of the ECC; however, it reduces the initial cracking load of the ECC, so that, in order to enhance the initial cracking strength, without compromising the strainhardening capacity of the ECC, the replacement rate of SCMs was maintained about $25 \%$. The fine aggregate of the ECC was replaced by BA at the rate of $10 \%, 20 \%$, and $30 \%$ and this substitution was made in the ternary binder ECC mixture (cement + FA + SL). According to the test method used by the Ministry of Environment in Korea [12], the leaching test was performed to identify any toxic material present in the BA and ecoefficient ECC developed using FA, SL, and BA. The influence of ecofriendly aggregates was evaluated based on the fresh concrete properties and mechanical properties.

\section{Materials and Testing Methods}

\subsection{Materials}

2.1.1. Binders: Ordinary Portland Cement (OPC), Fly Ash (FA), and Granulated Blast Furnace Slag (SL). OPC having a density and fineness of $3.15 \mathrm{~g} / \mathrm{cm}^{3}$ and $3,200 \mathrm{~cm}^{2} / \mathrm{g}$, respectively, was used. A class I type of FA obtained from a Korean thermal power plant was used and the average particle size of the FA was about $25 \mu \mathrm{m}$. The density and fineness of the FA were about $2.16 \mathrm{~g} / \mathrm{cm}^{3}$ and $3,645 \mathrm{~cm}^{2} / \mathrm{g}$, respectively. SL obtained from " $\mathrm{H}$ " company in Korea was used in this study. The average particle size, density, and fineness of the SL were $11 \mu \mathrm{m}, 2.94 \mathrm{~g} / \mathrm{cm}^{3}$, and $4,310 \mathrm{~cm}^{2} / \mathrm{g}$, respectively. Chemical analysis was performed for all types of binders and the composition is given in Table 1 .

2.1.2. Fine Aggregate: Silica Sand (SS) and Bottom Ash (BA). SS having an average and a maximum grain size of $110 \mu \mathrm{m}$ and $150 \mu \mathrm{m}$, respectively, was used. The density of the SS was about $2.64 \mathrm{~g} / \mathrm{cm}^{3}$ and the water absorption was about $1.01 \%$. The chemical composition of the SS is listed in Table 1. BA obtained from a thermal power plant located in Korea was 
TABLE 2: Mixture proportions of all ECC mixtures.

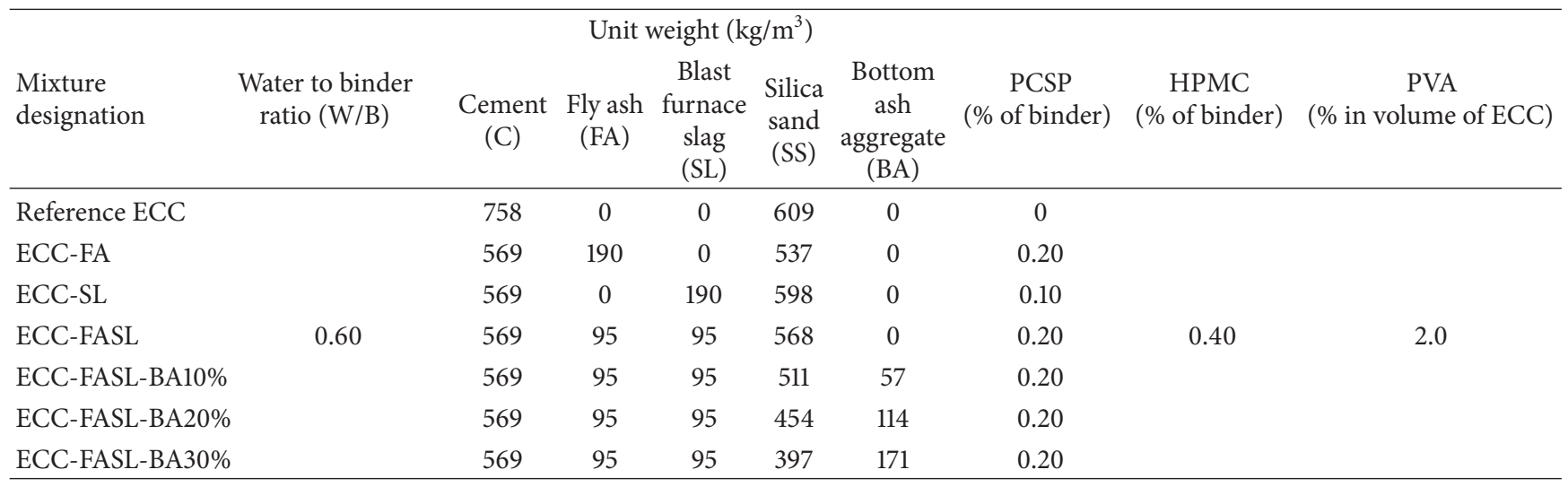

PCSP: polycarboxylic superplasticizer; HPMC: hydroxypropyl methylcellulose.

used in this study. The obtained BA was sieved and BA with a size of less than $1 \mathrm{~mm}$ was used. The density of BA was about $2.38 \mathrm{~g} / \mathrm{cm}^{3}$ and the water absorption of the BA was about $2.88 \%$, which is higher than that of the SS. The chemical analysis results showed that BA contains about $47.90 \%$ silica $\left(\mathrm{SiO}_{2}\right)$ and $25.94 \%$ alumina $\left(\mathrm{Al}_{2} \mathrm{O}_{3}\right)$, which is summarized in Table 1. The particle morphology of BA and SS showed that SS has a uniform size and nearly round shape, while the BA has a nonuniform size and a mixture of round and angular shapes.

2.1.3. Polyvinyl Alcohol (PVA) Fiber. Polyvinyl alcohol (PVA) fiber was used in this study to prepare the ECC mixture. The length and diameter of the fiber were about $12 \mathrm{~mm}$ and $40 \mu \mathrm{m}$, respectively. The tensile strength and elastic modulus of the fiber were 1,560 $\mathrm{MPa}$ and $37 \mathrm{GPa}$, respectively. The elongation and density of the fiber were about $6 \sim 10 \%$ and $1.3 \mathrm{~g} / \mathrm{cm}^{3}$, respectively.

2.1.4. Chemical Admixtures. The combination of polycarboxylic superplasticizer and hydroxylpropyl methylcellulose was used to improve the matrix fluid properties, resulting in an enhancement in the dispersion of reinforcing fibers.

2.2. Mixture Proportion and Specimen Preparation. Among the seven ECC mixtures, cement content of three mixtures was replaced with FA and SL at a replacement level of $25 \%$ (such as $75 \%$ cement $+25 \%$ FA, $75 \%$ cement $+25 \%$ SL, and $75 \%$ cement $+12.5 \% \mathrm{FA}+12.5 \% \mathrm{SL})$. The other three mixtures were prepared with BA at substitution rates of $10 \%$, $20 \%$, and $30 \%$ and this substitution was made in the ternary binder system $(80 \%$ cement $+12.5 \%$ FA $+12.5 \%$ SL $)$. The one remaining mixture was the reference mixture and had no SCMs or fine aggregate substitution. The water binder ratio was constantly maintained for all mixtures and the value was about 0.6. The detailed mix proportions of all mixtures are summarized in Table 2. All the ECC mixtures were prepared using a 15-liter mortar mixer with the same speed and time and were prepared at room temperature. Initially, the binding materials and fine aggregate were mixed at $100 \mathrm{rpm}$ for 1.5

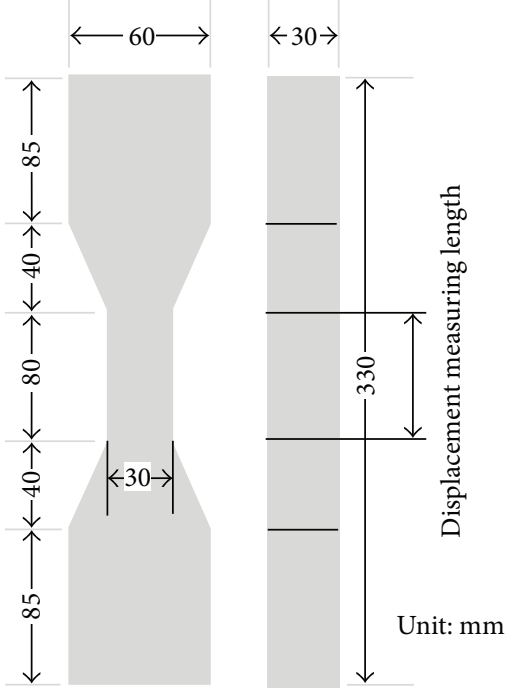

FIGURE 1: Details of specimen for direct tensile test (dog-bone shape).

minutes, followed by the water and admixtures being added to the dry mix and mixed at $200 \mathrm{rpm}$ for 3 minutes. After that, PVA fibers were added to the wet mixture and the mixture was mixed at $200 \mathrm{rpm}$ for 5 minutes to obtain a uniform ECC mixture. The influence of the SCMs binders and BA on the fresh concrete's properties was evaluated through the slump cone test and self-consolidating tests. After the measurement of fresh concrete properties, the specimens, including dogbone shaped specimens (see Figure 1), cylinders, and beam specimens were cast in the moulds for tensile, compression, and flexural tests. All specimens were prepared layer by layer and each layer was moderately compacted by the table vibrator. After casting of all specimens, the specimens were covered with a plastic sheet in order to avoid moisture loss. Specimens were then kept at room temperature for $24 \mathrm{hrs}$ and thereafter were demoulded and cured at room temperature of about $23^{\circ} \mathrm{C}$ for 28 days. To simplify the discussion of 
TABLE 3: Test method and equipment for detection analysis of harmful materials $[12,13]$.

\begin{tabular}{ll}
\hline Test items & Test methods and equipment \\
\hline $\mathrm{Cr}^{6+}$ & UV-Vis spectrophotometer \\
\hline $\mathrm{As}, \mathrm{Hg}$ & $\begin{array}{l}\text { AAS (atomic absorption } \\
\text { spectrophotometer) }\end{array}$ \\
\hline $\mathrm{Pb}, \mathrm{Cd}, \mathrm{Cu}, \mathrm{CN}$ & $\begin{array}{l}\text { ICP (inductive coupled plasma emission } \\
\text { spectrophotometer) }\end{array}$ \\
\hline $\mathrm{PCE}^{1}, \mathrm{TCE}^{2}, \mathrm{OP}^{3}$ & $\begin{array}{l}\text { ATD-GC/MS (automated thermal } \\
\text { desorption-gas-chromatography/mass } \\
\text { spectrophotometry) }\end{array}$ \\
\hline
\end{tabular}

$\overline{\mathrm{PCE}^{1} \text { : tetrachloroethylene, } \mathrm{TCE}^{2} \text { : trichloroethylene, and } \mathrm{OP}^{3} \text { : organophos- }}$ phates.

the mixtures, names were given to the mixtures, such as ECCFA, ECC-SL, ECC-FASL, ECC-FASL-BA10\%, ECC-FASLBA20\%, and ECC-FASL-BA30\%. For example, the name ECC-FASL-BA10\% indicates an ECC mixture substituted with a combination of FA and SL and 10\% of bottom ash.

\subsection{Test Methods}

\subsubsection{Fresh Properties}

(1) Slump Cone Test and Self-Consolidating Tests. The slump cone apparatus with top and bottom diameter of $100 \mathrm{~mm}$ and $200 \mathrm{~mm}$, respectively, was used. The height of the apparatus was about $300 \mathrm{~mm}$. The cone was placed on the flat surface and filled with ECC. The ECC was then allowed to flow by lifting up the cone. The average diameter of the ECC flow was measured along two diagonals [14].

To measure the self-consolidation of the ECC, a rectangular box with a size and height of $120 \mathrm{~mm} \times 200 \mathrm{~mm}$ and $400 \mathrm{~mm}$, respectively, was used, and the box was divided into two chambers using a center partition wall. A gate with a height of $80 \mathrm{~mm}$ was fixed in the bottom of the partition wall. Initially, the gate was closed and one chamber of the box was filled with ECC up to the height of $400 \mathrm{~mm}$. After the gate was removed, the flow of height ECC to the next chamber was measured [14].

2.3.2. Leaching Test for Hazardous Materials. Enforcement Regulation of the Waste Management Law [13] recommends the standard limits for deleterious substances present in the waste. In order to verify that limit, BA was subjected to a leaching test before it was used in ECC; in addition, the amount of deleterious substances present in the ecoefficient ECC developed using FA, SL, and BA was also evaluated. According to the procedure described in the Ministry of Environment waste process test method, the leaching test was performed. The test methods and equipment utilized for detection, specified in solid waste process test, Ministry of Environment Korea [12], are listed in Table 3.

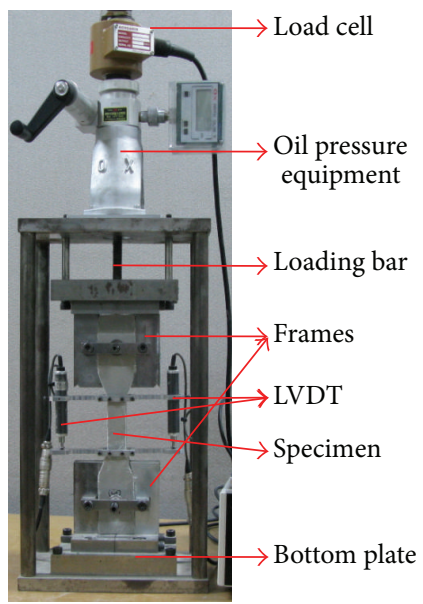

Figure 2: Direct tensile test setup.

\subsubsection{Mechanical Properties}

(1) Direct Tensile Test. In order to evaluate the influence of SCMs and BA on the tensile property of ECC, direct tensile tests were performed on dog-bone shaped specimens and the geometry of the specimens is presented in Figure 1. The tests were performed in a controlled manner with a loading rate of $0.2 \mathrm{~mm} / \mathrm{min}$. To measure the displacement of the specimens, two linear variable displacement transducers (LVDTs) with the gauge length of $10 \mathrm{~mm}$ were attached to the specimens. Figure 2 illustrates the experimental setup. During testing the crack formation and propagation and crack widths were observed and measured.

(2) Compressive Strength Test. To evaluate the compressive strength of ECC, cylinders with diameter $100 \mathrm{~mm}$ and height $200 \mathrm{~mm}$ were prepared and cured for 28 days at a temperature of $23 \pm 1^{\circ} \mathrm{C}$. After that, the specimens were tested on the universal testing machine (UTM) with a capacity of $1,000 \mathrm{kN}$. The test was performed according to the procedure described in KS F 2405 [15].

(3) Flexural Strength Test. According to the procedure described in KS F 2408 [16], flexural strength tests were performed on ECC beams. The ECC beam specimens with dimensions of $400 \mathrm{~mm} \times 100 \mathrm{~mm} \times 20 \mathrm{~mm}$ were prepared and cured for 28 days at room temperature. A four-point bending setup was adopted for testing and the tests were performed on a UTM with a capacity of $200 \mathrm{kN}$. Tests were performed until failure. The deflection of the beam was controlled at a loading rate of $0.5 \mathrm{~mm} / \mathrm{min}$ and the midspan deflection of the beams measured using two LVDTs with the gauge length of $25 \mathrm{~mm}$. The flexural strength of the ECC beam was calculated using

$$
f=\frac{(P \times l)}{\left(b \times d^{2}\right)},
$$

where $f$ is the flexural strength; $P$ is the maximum load; $l$ is the span length; and $b$ and $d$ are the width and height of the specimen, respectively. 
TABLE 4: Test results of slump cone and self-consolidation test of all ECC mixtures.

\begin{tabular}{|c|c|c|c|c|c|c|}
\hline \multirow{2}{*}{ Mixture designation } & \multicolumn{3}{|c|}{ Slump cone test } & \multicolumn{3}{|c|}{ Self-consolidation test } \\
\hline & $D_{1}(\mathrm{~mm})$ & $D_{2}(\mathrm{~mm})$ & $\mathrm{FI}(\Gamma)$ & $H(\mathrm{~mm})$ & $H_{0}(\mathrm{~mm})$ & $L$ \\
\hline Reference ECC & 655 & 650 & 9.6 & 157 & 400 & 0.78 \\
\hline ECC-FA & 660 & 655 & 9.8 & 160 & 400 & 0.80 \\
\hline ECC-SL & 690 & 685 & 10.8 & 180 & 400 & 0.90 \\
\hline ECC-FASL & 680 & 670 & 10.4 & 174 & 400 & 0.87 \\
\hline ECC-FASL-BA10\% & 620 & 610 & 8.4 & 150 & 400 & 0.75 \\
\hline ECC-FASL-BA20\% & 615 & 610 & 8.3 & 150 & 400 & 0.75 \\
\hline ECC-FASL-BA30\% & 595 & 590 & 7.8 & 140 & 400 & 0.70 \\
\hline
\end{tabular}

\section{Results and Discussions}

\subsection{Fresh Properties}

3.1.1. Slump Cone Test and Self-Consolidation Test. The results of the test of flow properties and self-consolidation of all ECC mixtures are summarized in Table 4. The flowability and the self-consolidation of ECC are presented in terms of flowability index $(\Gamma)$ and self-consolidating index $(L)$, respectively, and the following equations were used to calculate the flowability index $(\Gamma)$ and self-consolidating index $(L)$, respectively:

$$
\begin{gathered}
\Gamma=\frac{\left(D_{1} \times D_{2}\right)-D_{0}^{2}}{D_{0}^{2}}, \\
L=\frac{2 H}{H_{0}},
\end{gathered}
$$

where $D_{1}$ is the maximum diameter of the flow; $D_{2}$ is the diameter of flow perpendicular to $D_{1} ; D_{0}$ is the diameter of the slump cone $(200 \mathrm{~mm}) ; H_{0}$ is the initial height of the fresh ECC ( $400 \mathrm{~mm}) ; H$ is the flow of height ECC to the next chamber.

It was observed that the substitution of SCMs showed an advantageous effect on fresh concrete properties (both flow properties and self-consolidation), and in particular the substitution of SL and the combination of SCMs showed improved fresh concrete properties as shown in Figure 3. The slump flow of mixture ECC-FA $(\Gamma=9.8)$ was relatively equal to the slump flow of reference mixture $(\Gamma=9.6)$. However, the slump flows of mixtures ECC-SL and ECC-FASL $(\Gamma=10.8$ and $\Gamma=10.4$ ) were higher than that of the reference mixture by $12.03 \%$ and $7.88 \%$, respectively. The self-consolidating test also exhibited the perfect self-consolidation of mixtures ECC-SL and ECC-FASL of 0.90 and 0.87, respectively, which was $15.38 \%$ and $11.54 \%$, respectively, higher than that of the reference mixture. The SCMs substitution contributed to the improved uniform fiber dispersion and as a result improved the fresh concrete properties observed. As shown in Figure 3, the substitution of BA in the ECC potentially affects the fresh concrete properties of the ECC; in particular, the increase in BA decreases the fresh concrete properties further. However, the flow and self-consolidation properties of mixture ECC-FASL-BA10\% are very similar to those of the reference mixture. The decrease in fresh concrete properties with the substitution of BA is attributed to the higher water absorption and the irregular shape of the BA. The increased water absorption property of the BA has increased the water demand in the ECC. In addition, the irregular shape and big particle size of BA created more friction against the flow of ECC, and as a result the workability of the ECC developed using BA decreased with the increase in the BA substitution rate. For example, the substitution of $10 \%$ of BA decreased the self-consolidation by $16.10 \%$, when compared to the mixture ECC-FASL. On the other hand, the mixture ECC-FASLBA30\% decreased its self-consolidation by $24.29 \%$. A similar trend was observed in the flowability test.

3.2. Leaching Test for Hazardous Materials. The results of leaching tests of BA and the ECC developed using FA, SL, and BA are summarized in Table 5. The results were compared with the limit for deleterious substances specified in the Enforcement Regulation of the Waste Management Law in Table 5. It was observed that the deleterious substances $\left(\mathrm{Cr}^{6+}\right.$, As, $\mathrm{Cd}, \mathrm{Pb}, \mathrm{Cu}, \mathrm{CN}, \mathrm{Hg}, \mathrm{PCE}, \mathrm{TCE}$, and $\mathrm{OP}$ ) present in the $\mathrm{BA}$ were very negligible, and in particular, the substances $\mathrm{CN}$, $\mathrm{Hg}$, PCE, TCE, and OP were not detectable, when compared to the limit value specified in the Enforcement Regulation of the Waste Management Law [13]. From this observation, it can be inferred that there are no harmful substances present in the BA, suggesting that BA can be effectively used as a substitute or alternative material in ECC applications. The results of leaching tests of ECC developed using FA, SL, and $\mathrm{BA}$ also revealed that the presence of deleterious substances is very negligible; in addition, many substances, specifically $\mathrm{Cr}^{6+}$, As, Cd, CN, PCE, TCE, and OP, are not detectable. As can be seen from Table 5, the presence of deleterious substances in BA was reduced with the substitution in ECC. From the above observation, it can be inferred that SCMs and BA can be effectively used as an alternative material to develop the ecoefficient ECC. 


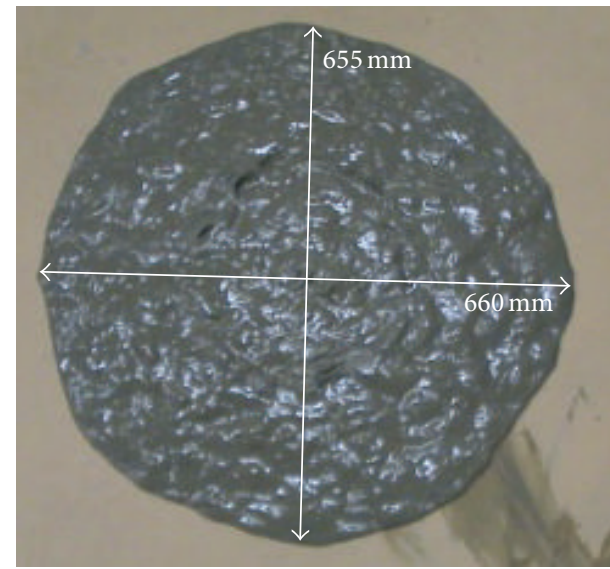

(a)

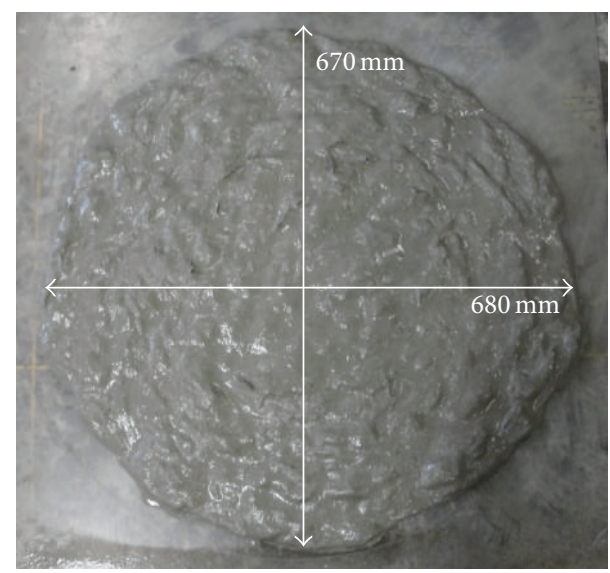

(c)

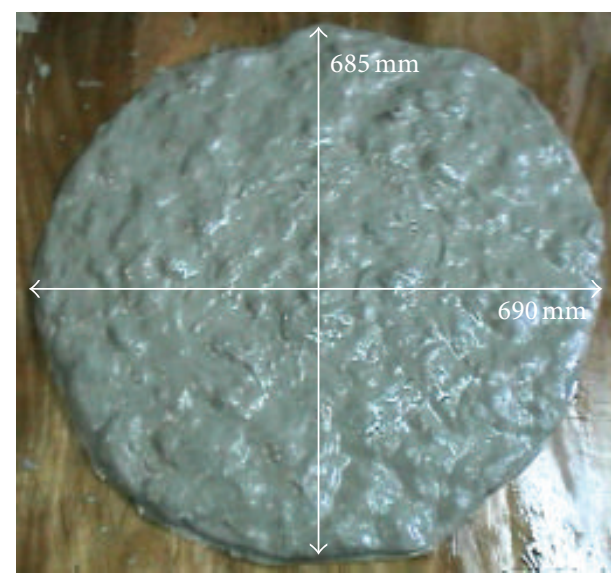

(b)

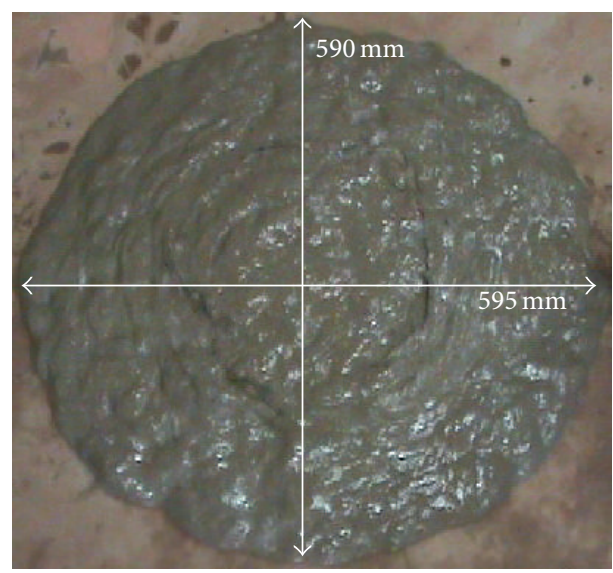

(d)

Figure 3: Slump flow behavior of ECC.

TABLE 5: Environment criteria and detection amount of harmful materials by solid waste management law.

\begin{tabular}{|c|c|c|c|c|c|c|c|c|c|c|}
\hline \multirow{2}{*}{$\begin{array}{l}\text { Mixture } \\
\text { designation }\end{array}$} & \multicolumn{10}{|c|}{ Test items unit: $\mathrm{mg} / \mathrm{L}$} \\
\hline & $\mathrm{Cr}^{6+}$ & As & $\mathrm{Cd}$ & $\mathrm{Pb}$ & $\mathrm{Cu}$ & $\mathrm{CN}$ & $\mathrm{Hg}$ & PCE & TCE & OP \\
\hline $\begin{array}{l}\text { Environment } \\
\text { criteria }\end{array}$ & 1.5 & 1.5 & 0.3 & 3 & 3 & 1 & 0.005 & 0.1 & 0.3 & 1 \\
\hline $\mathrm{BA}$ & 0.055 & 0.045 & 0.005 & 0.097 & 0.179 & Not detected & 0.000543 & Not detected & Not detected & Not detected \\
\hline ECC-FA & Not detected & Not detected & 0.001 & 0.002 & 0.052 & Not detected & 0.000062 & Not detected & Not detected & Not detected \\
\hline ECC-SL & Not detected & Not detected & Not detected & 0.004 & 0.039 & Not detected & 0.000067 & Not detected & Not detected & Not detected \\
\hline $\begin{array}{l}\text { ECC-FASL- } \\
\text { BA20\% }\end{array}$ & Not detected & Not detected & 0.002 & 0.003 & 0.049 & Not detected & 0.000044 & Not detected & Not detected & Not detected \\
\hline
\end{tabular}

\subsection{Mechanical Properties}

3.3.1. Direct Tensile Test. The tensile properties including maximum tensile strain and ultimate tensile stress are summarized in Table 6. The uniaxial tensile behavior of all ECC mixtures is presented in Figure 4. It was observed that all of the ECC mixtures exhibited an apparent multiple cracking pattern that accompanied pseudo strain-hardening behavior with the strain capacities ranging from $1.4 \%$ to nearly $3.5 \%$. The ECC developed by FA with the substitution rate of $25 \%$ (ECC-FS) exhibited a strain capacity of 3.3\%, and its ductility was also higher than that of the reference ECC mixture, as shown in Figure 4. However, the FA did not have an influence on the strength properties; significantly, it lowered the tensile strength development when compared to the reference ECC mixture, finding that was compatible with the previous research results $[2,7]$. The substitution of FA in ECC enhanced the frictional bond at the interface between the fiber and matrix and reduced the fiber/matrix interface chemical bond and the matrix toughness $[1,7]$. As a result, the ECC-FA mixture exhibited a lower tensile strength and a higher tensile strain/ductility capacity. The 
TABLE 6: Mechanical properties of all ECC mixtures.

\begin{tabular}{|c|c|c|c|c|c|}
\hline \multirow[b]{2}{*}{ Mixture designation } & \multicolumn{2}{|c|}{ Uniaxial tensile properties } & \multicolumn{2}{|c|}{ Compressive strength ( $\mathrm{MPa})$} & \multirow[b]{2}{*}{$\begin{array}{l}\text { Maximum deflection } \\
\text { in flexure (mm) }\end{array}$} \\
\hline & $\begin{array}{l}\text { Maximum average } \\
\text { tensile stress (MPa) }\end{array}$ & $\begin{array}{l}\text { Maximum average } \\
\text { tensile strain (\%) }\end{array}$ & 7 days & 28 days & \\
\hline Reference ECC & 3.7 & 2.7 & 28.36 & 31.81 & 14.50 \\
\hline ECC-FA & 3.4 & 3.3 & 28.12 & 30.05 & 17.02 \\
\hline ECC-SL & 4.0 & 3.2 & 29.14 & 32.56 & 16.12 \\
\hline ECC-FASL & 3.9 & 3.5 & 29.56 & 32.84 & 18.31 \\
\hline ECC-FASL-BA10\% & 4.0 & 3.3 & 30.21 & 33.12 & 15.56 \\
\hline ECC-FASL-BA20\% & 4.4 & 2.1 & 30.94 & 34.91 & 12.56 \\
\hline ECC-FASL-BA30\% & 4.7 & 1.4 & 30.98 & 35.79 & 9.56 \\
\hline
\end{tabular}

substitution of SL increased the tensile strain capacity of the ECC (3.4\%) and also enhanced the tensile strength capacity $(4.0 \mathrm{MPa})$ of the ECC compared to those of the reference ECC mixture, which achieved the tensile strain and strength capacity of $2.7 \%$ and $3.7 \mathrm{MPa}$, respectively. The presence of slag particles contributed to the enhancement of the workability of the ECC, resulting in improved fiber dispersion. As a result, a higher enhancement in tensile strain and strength was observed. This tendency can be confirmed by fiber dispersion tests. Figure 5 shows the fiber dispersion analysis results achieved through cross-sectional fluorescence image analysis [10]. From Figure 5, it can be understood that the slag particles provide a driving force for the mortar matrix flow, which led to the improved fiber dispersion.

A comparison of the influence of FS and SL on the tensile behavior of ECC was presented in Figure 4. From Figure 4, it can be understood that the substitution of FA, while enhancing the tensile strain capacity of the ECC, showed a lower tensile strength. In contrast, the ECC with SL showed a higher tensile strength but exhibited a tensile strain of $3.2 \%$, which is $3.13 \%$ lower than the ECC developed using FA. From the above results, it can be inferred that the tensile strain and tensile strength of ECC can be improved using FA and SL, respectively. Based on this outcome, the ECC was developed using a ternary binding system (75\% cement $+12.5 \% \mathrm{FA}+12.5 \% \mathrm{SL})$ and the stress-strain behavior of the ECC developed using a ternary binding system is shown in Figure 4. As expected, the combination of FA and SL significantly improved the axial strain and strength capacity of the ECC, when compared to the reference ECC and the ECC developed using FA and SL. For example, the ECC developed using a ternary binding system achieved a tensile strain and strength of $3.5 \%$ and $3.9 \mathrm{MPa}$, respectively. On the other hand, the ECC developed using FA achieved a tensile strain and strength of $3.3 \%$ and $3.4 \mathrm{MPa}$, respectively, which are $6.06 \%$ and $14.71 \%$ lower. Similarly, the ECC developed using SL showed a decrease in tensile strain of 9.38\% compared to that of the ECC developed using a ternary binding system. The presence of the FA in the ternary ECC leads to an increase in the frictional bond at the interface between PVA fibers and matrix and the presence of SL improved the fiber dispersion in the ECC. As a result the ECC developed using a ternary binding system exhibited higher ductility and strength than those of the ECC developed using a binary binding system. Huang et al. [1] achieved an initial cracking strength and strain-hardening capacity of $2.5 \mathrm{MPa}$ and $4.0 \%$, respectively, with the FA substitution of $70 \%$. In similar manner, the test results of $[3,7,10,11]$ demonstrate that the increase in the FA content did not influence the tensile strength of the ECC. Nevertheless, the ECC developed in this study using ternary binder system achieved a strain-hardening capacity and strength of 3.5\% and 3.9 $\mathrm{MPa}$, respectively. From this observation, it can be inferred that the ductility and the strength capacity of the ECC can be improved using a combination of different SCMs, particularly with the combination of FA and SL.

Since the ternary binder system exhibited superior performance, the BA substitution was made in the ECC developed using a ternary binder system with substitution rate of $10 \%, 20 \%$, and $30 \%$. The tensile behavior of the ECC developed using BA is shown in Figure 4. It was observed that all ECC mixtures developed using BA exhibited a strainhardening behavior; however, substitution of BA can potentially reduce the tensile behavior of the ECC; in addition, the tensile capacity was decreased with the increase in the BA substation rate. However, the ECC developed using BA with a substitution rate of $10 \%$ exhibited a strain capacity that was relatively equal to the strain capacity of ECC-FASL. For instance, the mixture ECC-FASL-BA10\% showed a strain value of $3.3 \%$, which is only $6.06 \%$ less than that of the ECCFASL. However, the mixture ECC-FASL-BA30\% achieved a strain capacity of $1.4 \%$ which is $150.06 \%$ less than that of the ECC-FASL. As compared to SS, the particle size of the BA was relatively high, and this particle size significantly affects the fiber dispersion, which is associated with workability (as was discussed earlier). In addition, the higher particle size reduces the available space for fiber dispersion and also increased the matrix fracture toughness by suppressing the margins between cracking strength and fiber bridging capacity and between crack tip toughness and complementary energy of fiber bridging. As a result, it lowers the tensile capacity. The distinctive characteristic of the ECC is the formation of multiple microcracks under tensile loading. Figure 6 shows the crack pattern of mixture ECC-FASL and ECC mixture developed using BA with various substitutions. From Figure 6 it can be understood that the mixture ECC-FASL exhibited a higher number of microcracks, and the crack widths were in the range of $25 \mu \mathrm{m} \sim 50 \mu \mathrm{m}$. Nevertheless, as can be seen 

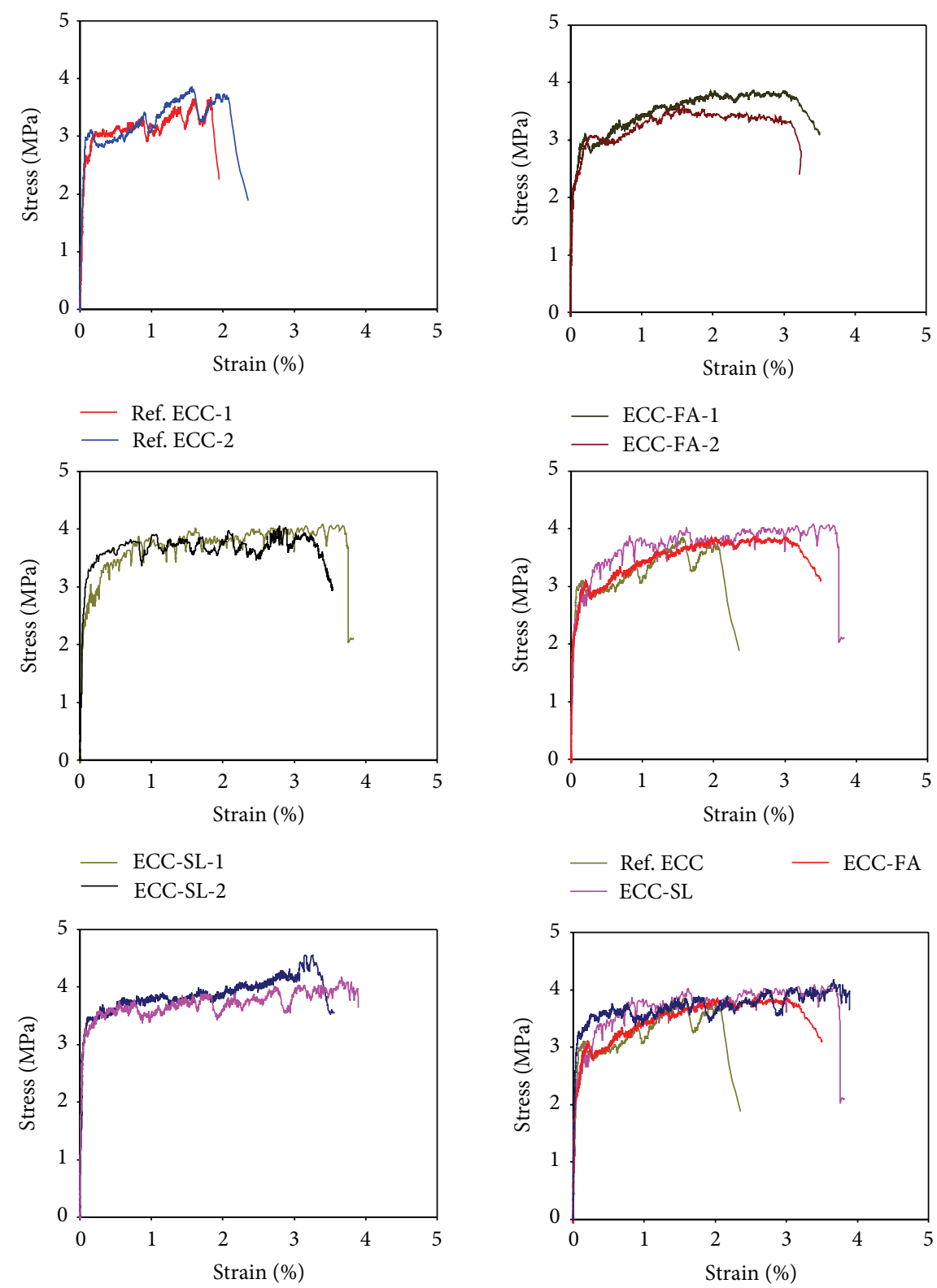

ECC-FASL-1
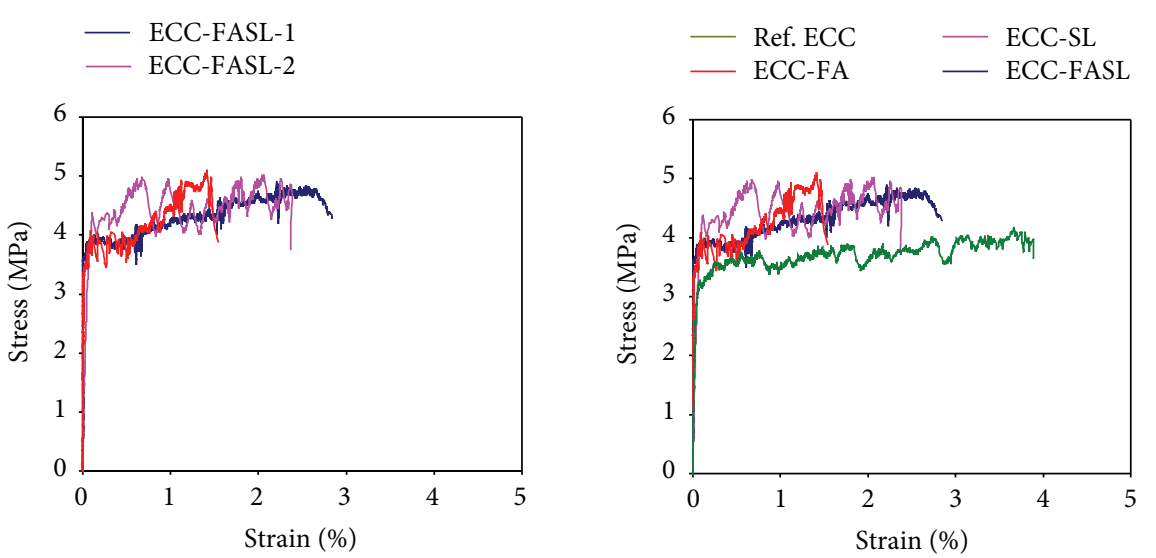

— ECC-FASL-BA10\% — ECC-FASL-BA20\% ECC-FASL-BA10\% — ECC-FASL-BA20\% — ECC-FASL-BA30\% - ECC-FASL-BA30\% — ECC-FASL

FIGURE 4: Uniaxial tensile stress-strain behavior of all ECC mixtures and comparison. 


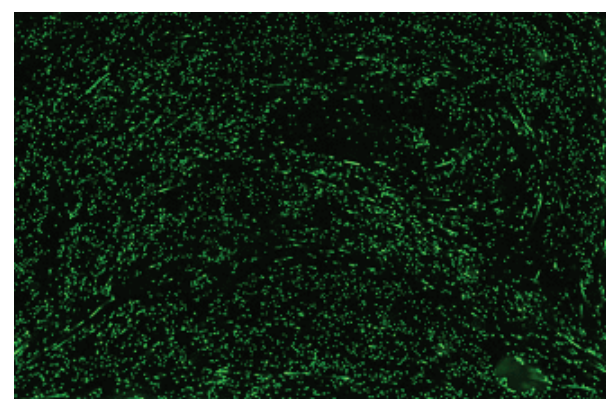

FIGURE 5: Cross-sectional fluorescence image of ECC-SL mixture [10].

from Figure 6, the substitution of BA reduced the number of microcracks; furthermore, the increase in the BA substitution rate leads to a decrease in the number of microcracks and the crack width. The average crack width of the mixtures ECCFASL-BA10\%, ECC-FASL-BA20\%, and ECC-FASL-BA30\% was less than $25 \mu \mathrm{m}$. The decrease in the number of microcracks with the substitution may be due to the higher particle size of the BA, and this size increases the matrix fracture toughness by increasing the tortuosity of fracture path along the transition zone between BA and cement paste, thus decreasing the microcracks and the crack width. From this observation, it can be inferred that the replacing of SS by $\mathrm{BA}$ with the substitution rate of $10 \%$ can be effectively used in ECC preparation. In addition, the decrease in the particle size of BA may have a more beneficial effect on the strainhardening capacity of ECC.

3.3.2. Compressive Strength. The 28-day compressive strength of all mixtures is presented in Figure 7. It was observed that the substitution of SCMs (FA and SL) did not have any negative effects on the compressive strength of ECC; in addition, the compressive strength of the mixtures developed using binary and ternary cementitious materials was relatively equal to the compressive strength of the reference mixture. It is well documented that the slower secondary hydration of SCMs decreases the compressive strength of the concrete mixtures. However, even though the substitution of SCMs might affect the secondary hydration of ECC, the SCMs contributed to an enhancement of the workability of the ECC, resulting in improved fiber dispersion and this tendency was confirmed by the fiber dispersion tests in the previous chapter. As a result, the compressive strength of the mixtures ECC-FA, ECC-SL, and ECC-FASL was not decreased significantly. From Figure 7, it can be understood that the ECC developed using SL showed a slightly higher strength than that of the FA. At the age of 28 days, the mixture ECC-FA exhibited a strength of $30.05 \mathrm{MPa}$, whereas the mixture ECC-SL achieved a strength of $32.56 \mathrm{MPa}$, which is $8.35 \%$ higher. As shown in Figure 7, the mixture ECC-FASL showed an enhancement in compressive strength compared to the mixtures ECC-FA and ECC-SL; however the enhancement was not significantly higher. Compared to the mixtures ECC-FA and ECC-SL, the compressive strength of ECC-FASL was enhanced by $9.28 \%$ and $1.01 \%$, respectively, at the age of 28 days. It was observed that the substitution of BA in the ECC-FASL mixture enhanced the compressive strength further; moreover, the increase in the substitution rate of $\mathrm{BA}$ increases the compressive strength. This increase in compressive strength may be due to the higher particle size and irregular shape of the BA. The irregular shape of the BA led to stiffer bonding, which may increase the compressive strength. Compared to the mixture ECC-FASL, at the age of 28 days, the mixtures ECC-FASL-BA10\%, ECCFASL-BA20\%, and ECC-FASL-BA30\% showed a compressive strength of $33.12 \mathrm{MPa}, 34.91 \mathrm{MPa}$, and $35.79 \mathrm{MPa}$, respectively, which are $1.01 \%, 6.31 \%$, and $8.98 \%$ higher, respectively. It is well documented that the compressive strength of the ECC is inversely proportional to the deformation (i.e., strainhardening). The compressive strength results obtained in this study showed fairly good agreement. From Table 6, it can be observed that when the 28-day compressive strength of ECC mixtures (ECC-FA, ECC-SL, ECC-FASL, and ECC-FASL-BA10\%) is in the range of $33 \mathrm{MPa}$, or less, the deformation/tensile strain of the ECC mixtures was in the range of $2.7 \%$ to $3.5 \%$. Nevertheless, when the ECC mixtures (ECC-FASL-BA20\% and ECC-FASL-BA30\%) exhibited a compressive strength ranging from $33 \mathrm{MPa}$ to $35 \mathrm{MPa}$, the deformation of the ECC drastically reduced to range from $1.4 \mathrm{~mm}$ to $2.1 \mathrm{~mm}$. From this observation, it can be inferred that, by controlling the compressive strength of ECC, a higher amount of strain-hardening behavior can be obtained. In addition, the replacement of SS by BA with a substitution rate of $10 \%$ can be made in ECC preparation without compromising the strain-hardening behavior.

3.3.3. Flexural Deflection Capacity. The deflection of all ECC mixtures corresponding to the ultimate flexural strength is summarized in Table 6. Figure 8 shows the flexural loaddeflection behavior of all ECC mixtures. The flexural deflection capacity of the ECC beam reflects the ductile behavior of that ECC mixture [3]. The flexural test results obtained were fairly consistent with the uniaxial tensile behavior and in addition the correlation between the uniaxial strain and the flexural deflection was quite strong, which can be recognized from Table 6. It was observed that all of the ECC mixtures developed using SCMs and BA exhibited a deflection hardening behavior. From Figure 8, it can be understood that the substitution of SCMs in the ECC enhanced the deflection hardening behavior; particularly the deflection hardening behavior of mixtures was ECC-FASL outperformed as is shown in Figure 9. The mixtures ECC-FA, ECC-SL, and ECCFASL increased their deflection capacity by $17.37 \%, 10.48 \%$, and $26.27 \%$, respectively, compared to the reference mixture. Comparing the mixtures ECC-FA and ECC-SL with one another, the mixture ECC-FA had the most beneficial effect on deflection capacity. The mixture ECC-FA enhanced its deflection capacity by $5.58 \%$, compared to ECC-SL. The enhancement in deflection capacity is attributed to the improvement in workability resulting from improved fiber dispersion, which led to the improvement in deflection. Compared to the binary binding system, the mixture ECC-FASL exhibited higher flexural strength and deflection capacity. The 


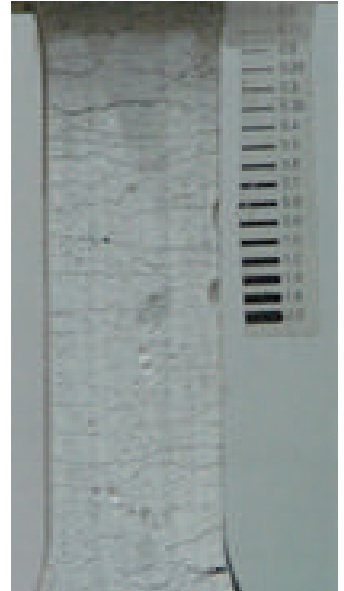

(a)

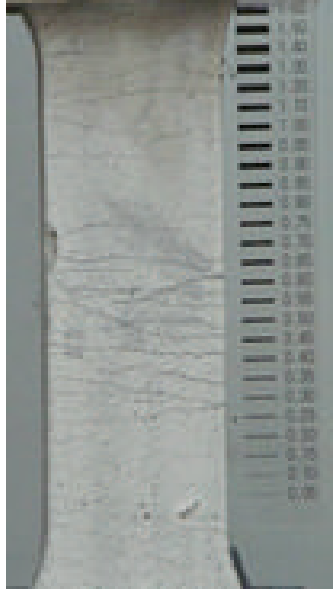

(b)

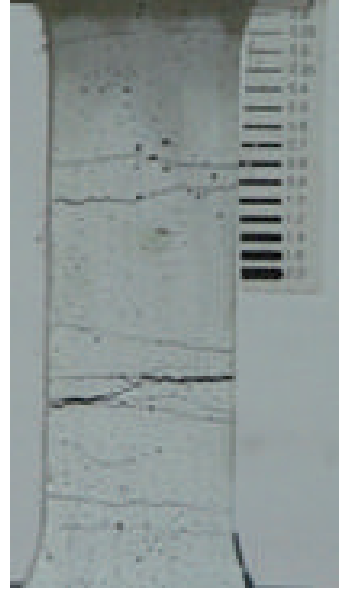

(c)

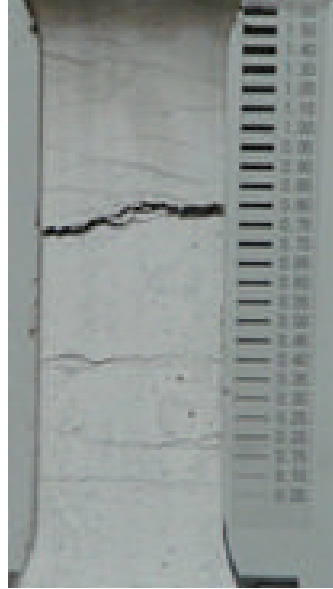

(d)

FIgURE 6: Crack behavior/pattern of ECC. (a) ECC-FASL, (b) ECC-FASL-BA10\%, (c) ECC-FASL-BA20\%, and (d) ECC-FASL-BA30\%.

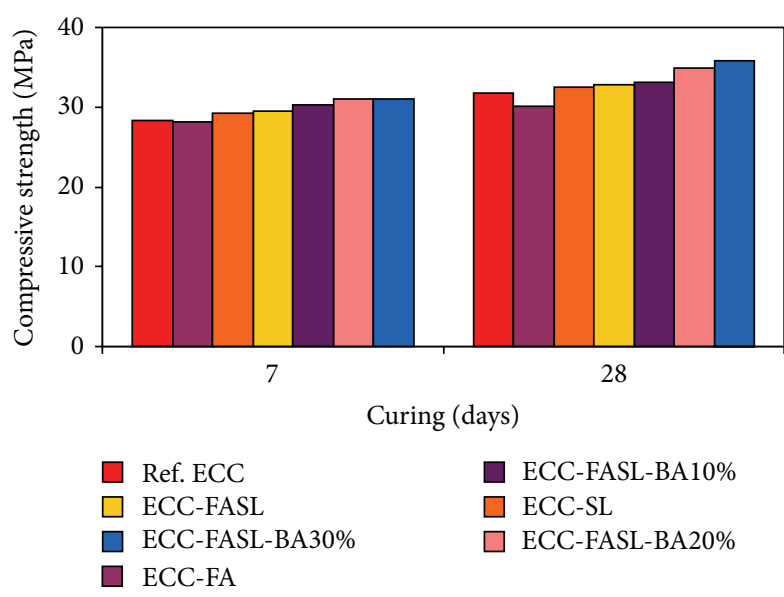

FIGURE 7: Compressive strength of all ECC mixtures and comparison.

mixture ECC-FASL enhanced its deflection capacity by $7.57 \%$ and $13.35 \%$, compared to that of the mixtures ECC-FA and ECC-SL, respectively. As discussed earlier, the presence of the FA in the ternary ECC leads to an increase in frictional bond at the interface between PVA fibers and matrix and the presence of SL improved the fiber dispersion in the ECC. As a result the ECC developed using a ternary binding system exhibited a higher deflection capacity than that of the ECC developed using a binary binding system. It was observed that the substitution of BA decreases the deflection capacity of the ECC mixtures; in addition the deflection capacity was decreased with the increase in the substitution rate. However, the deflection capacity of the mixture FASL-BA10\% was relatively similar to that of the mixture ECC-FASL and this mixture decreased its deflection capacity by only $17.67 \%$ compared to that of the ECC-FASL. The bigger particle size of the BA increased the matrix fracture toughness by increasing the tortuosity of the fracture path along the transition zone between BA and cement paste. As a result, it decreased the deflection capacity and microcrack formation.

\section{Conclusion}

An attempt was made to develop the ecoefficient ECC using FA and SL as a binder and a BA as a fine aggregate. The effects of SCMs and BA aggregate on fresh concrete properties and mechanical properties were experimentally investigated through tests including direct tensile test, compressive strength test, and flexural strength test. Based on the results obtained from the seven various ECC mixtures the following conclusions can be made.

(i) The substitution of SCMs had an advantageous effect on fresh concrete properties; significantly, the mixtures ECC-SL and ECC-FASL had slump flows that were increased by $12.03 \%$ and $7.88 \%$, respectively, when compared to the reference mixture.

(ii) The increased water absorption property of the BA increased the water demand in the ECC, and the irregular shape and big particle size of BA created more friction against the flow of ECC, leading to a decrease in workability with the increase in the BA substitution rate.

(iii) The presence of deleterious substances in the ECC developed using FA, SL, and BA was very negligible; furthermore, the presence of deleterious substances in $\mathrm{BA}$ was reduced with the substitution in ECC.

(iv) The substitution of FA and SL in ECC potentially enhanced the strain-hardening behavior of the ECC and mixtures ECC-FA and ECC-SL showed a strain capacity of $3.3 \%$ and $3.4 \%$, respectively.

(v) The ECC mixture developed using the combination of FA and SL had significantly improved axial strain and strength capacity compared to those of the individual ECC mixtures developed using FA and SL separately. 

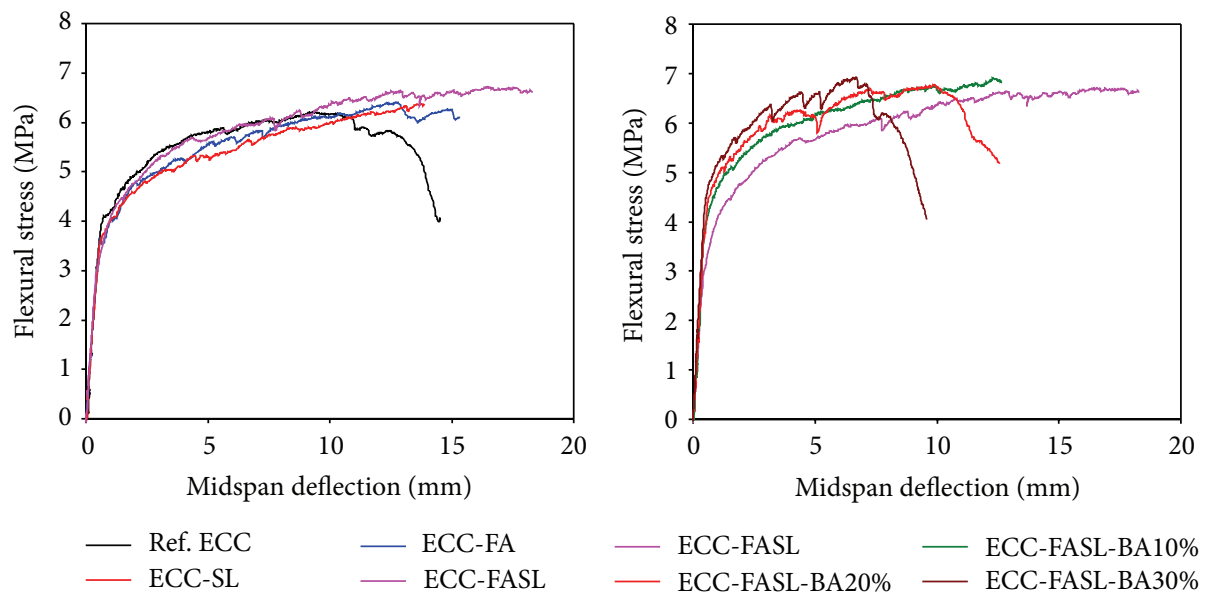

Figure 8: Flexural stress-midspan deflection behavior of all ECC mixtures and comparison.

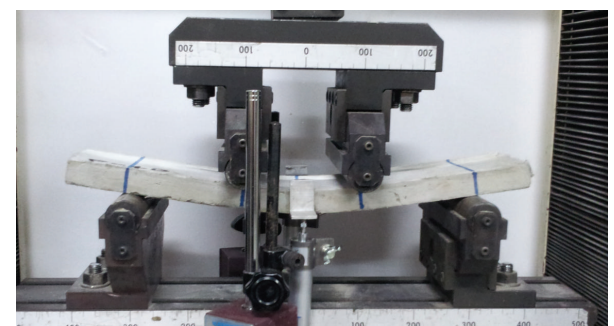

Figure 9: Flexural deflection of ECC-FASL mixture.

(vi) The mixture ECC-FASL had strain capacity that was enhanced by $6.06 \%$ and $9.38 \%$ compared to the mixtures ECC-FA and ECC-SL, respectively, and it was inferred that the ductility and the strength capacity of the ECC can be improved by using a combination of different SCMs, particularly with the combination of FA and SL.

(vii) The substitution of BA adversely affects the strain capacity of the ECC; moreover, the increase in the substitution rate of $\mathrm{BA}$ further reduces the strain capacity. However, mixture ECC-FASL-BA10\% showed a strain value of $3.3 \%$, which is only $6.06 \%$ less than the ECC-FASL.

(viii) The substitution of SCMs did not affect the compressive strength of the ECC; moreover, the SCMs increased the fiber distribution in ECC and achieved a relatively equal compressive strength to the reference mixture. In addition, the substitution of BA increased the compressive strength of ECC.

(ix) Compared to the reference mixture, the ECC mixture developed using SCMs showed an improved deflection capacity; however, the substitution of BA reduces the deflection capacity of the ECC beam. In addition the trend of deflection capacity was fairly similar to that of uniaxial tensile capacity. (x) Based on the test results, it is recommended that a combination of SCMs (12.5\% FA and $12.5 \% \mathrm{SL})$ and the BA aggregate with the substitution rate of $10 \%$ can be effectively used in ECC preparation.

\section{Conflict of Interests}

The authors declare that there is no conflict of interests regarding the publication of this paper.

\section{Acknowledgments}

This work (2014-0750-01) was supported by research fund of Chungnam National University. The financial support is gratefully acknowledged.

\section{References}

[1] X. Huang, R. Ranade, W. Ni, and V. C. Li, "Development of green engineered cementitious composites using iron ore tailings as aggregates," Construction and Building Materials, vol. 44, pp. 757-764, 2013.

[2] Y. Zhu, Z. Zhang, Y. Yang, and Y. Yao, "Measurement and correlation of ductility and compressive strength for engineered cementitious composites (ECC) produced by binary and ternary systems of binder materials: fly ash, slag, silica fume and cement," Construction and Building Materials, vol. 68, pp. 192198, 2014.

[3] N. M. Altwair, M. A. Megat Johari, and S. F. Saiyid Hashim, "Flexural performance of green engineered cementitious composites containing high volume of palm oil fuel ash," Construction and Building Materials, vol. 37, pp. 518-525, 2012.

[4] V. Saraswathy and H.-W. Song, "Corrosion performance of rice husk ash blended concrete," Construction and Building Materials, vol. 21, no. 8, pp. 1779-1784, 2007.

[5] V. Saraswathy, S. Muralidharan, K. Thangavel, and S. Srinivasan, "Influence of activated fly ash on corrosion-resistance and strength of concrete," Cement \& Concrete Composites, vol. 25, no. 7, pp. 673-680, 2003. 
[6] R. O. Lane and J. F. Best, "Properties and use of fly ash on Portland cement concrete," Concrete International, vol. 4, no. 7, pp. 81-92, 1982.

[7] M. Şahmaran and V. C. Li, "Durability properties of microcracked ECC containing high volumes fly ash," Cement and Concrete Research, vol. 39, no. 11, pp. 1033-1043, 2009.

[8] N.-Q. Feng, Y.-X. Shi, and T.-Y. Hao, "Influence of ultra-fine powder on the fluidity and strength of cement paste," Advances in Cement Research, vol. 12, no. 3, pp. 89-95, 2000.

[9] Z. Yu, Y. Yang, X. Gao, H. Deng, and Y. Yao, "Mechanical properties of engineered cementitious composites with high volume fly ash," Journal of Wuhan University of Technology, vol. 24, pp. 166-170, 2009.

[10] J.-K. Kim, J.-S. Kim, G. J. Ha, and Y. Y. Kim, “Tensile and fiber dispersion performance of ECC (engineered cementitious composites) produced with ground granulated blast furnace slag," Cement and Concrete Research, vol. 37, no. 7, pp. 1096-1105, 2007.

[11] S. Wang and V. C. Li, "Engineered cementitious composites with high-volume fly ash," ACI Materials Journal, vol. 104, no. 3, pp. 233-241, 2007.

[12] Ministry of Environment (Korea), Solid Waste Process Test Methods, 2007.

[13] Ministry of Government Legislation (Korea), Appendix 1 of the Enforcement Rule of the Wastes Control Act, Ministry of Government Legislation (Korea), 2007.

[14] H.-J. Kong, S. G. Bike, and V. C. Li, "Constitutive rheological control to develop a self-consolidating engineered cementitious composite reinforced with hydrophilic poly(vinyl alcohol) fibers," Cement \& Concrete Composites, vol. 25, no. 3, pp. 333341, 2003.

[15] Korean Standards Association, Standard Test Method for Compressive Strength of Concrete, KS F 2405, Korean Standards Association, Seoul, Republic of Korea, 2010.

[16] Korean Standards Association, Method of Test for Flexural Strength of Concrete, KS F 2408, Korean Standards Association, 2010. 

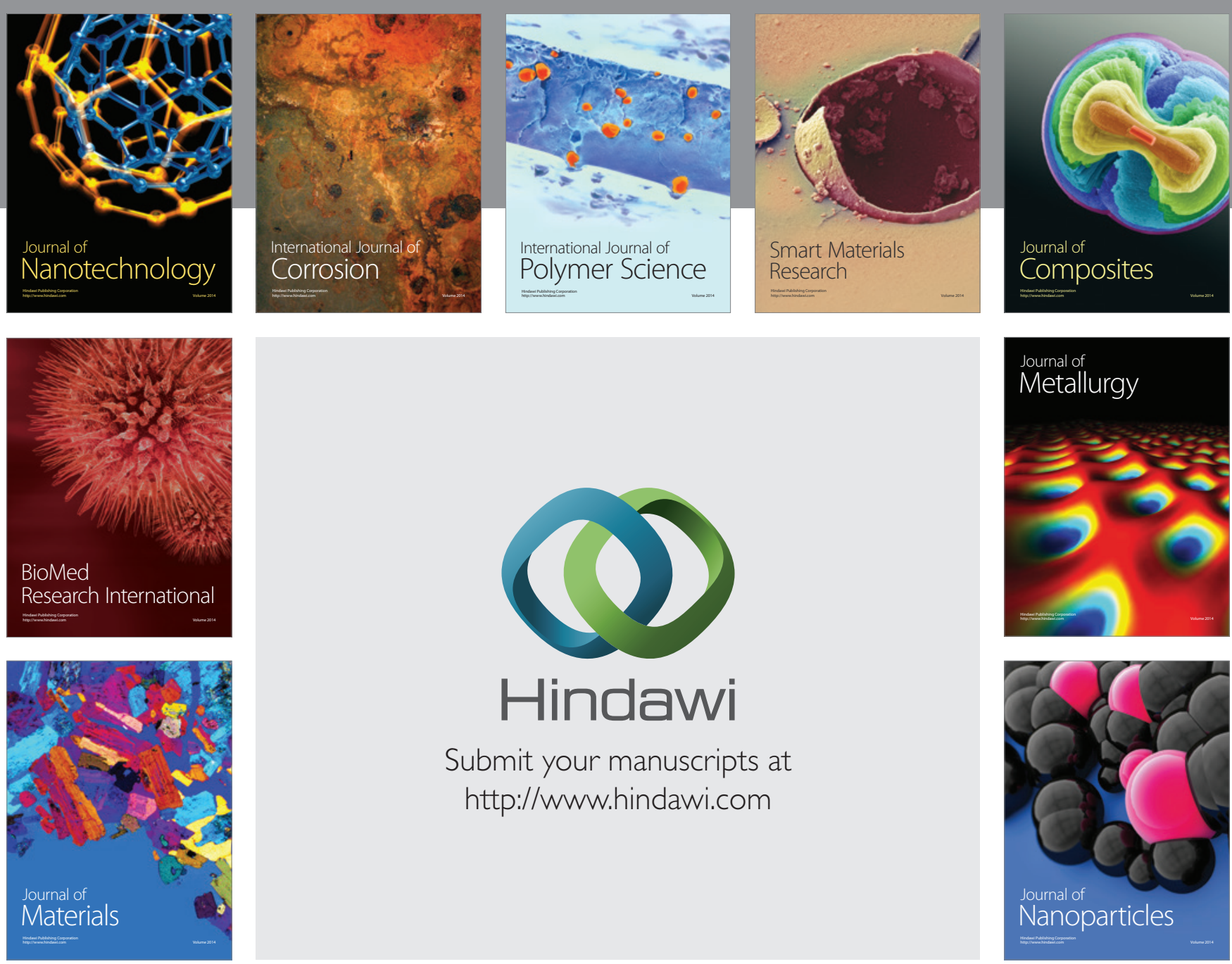

Submit your manuscripts at http://www.hindawi.com
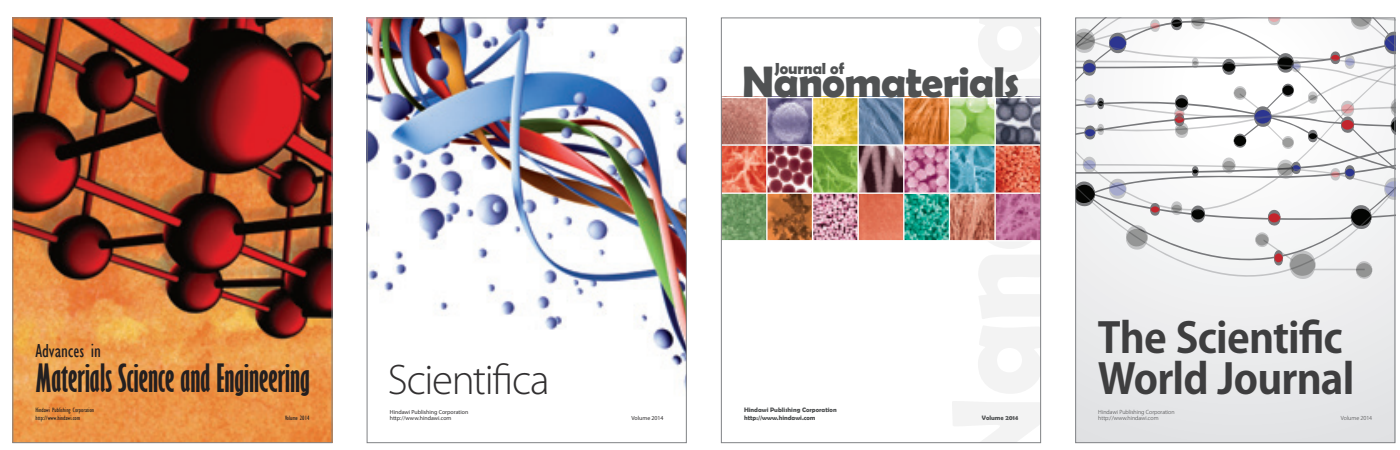

\section{The Scientific World Journal}
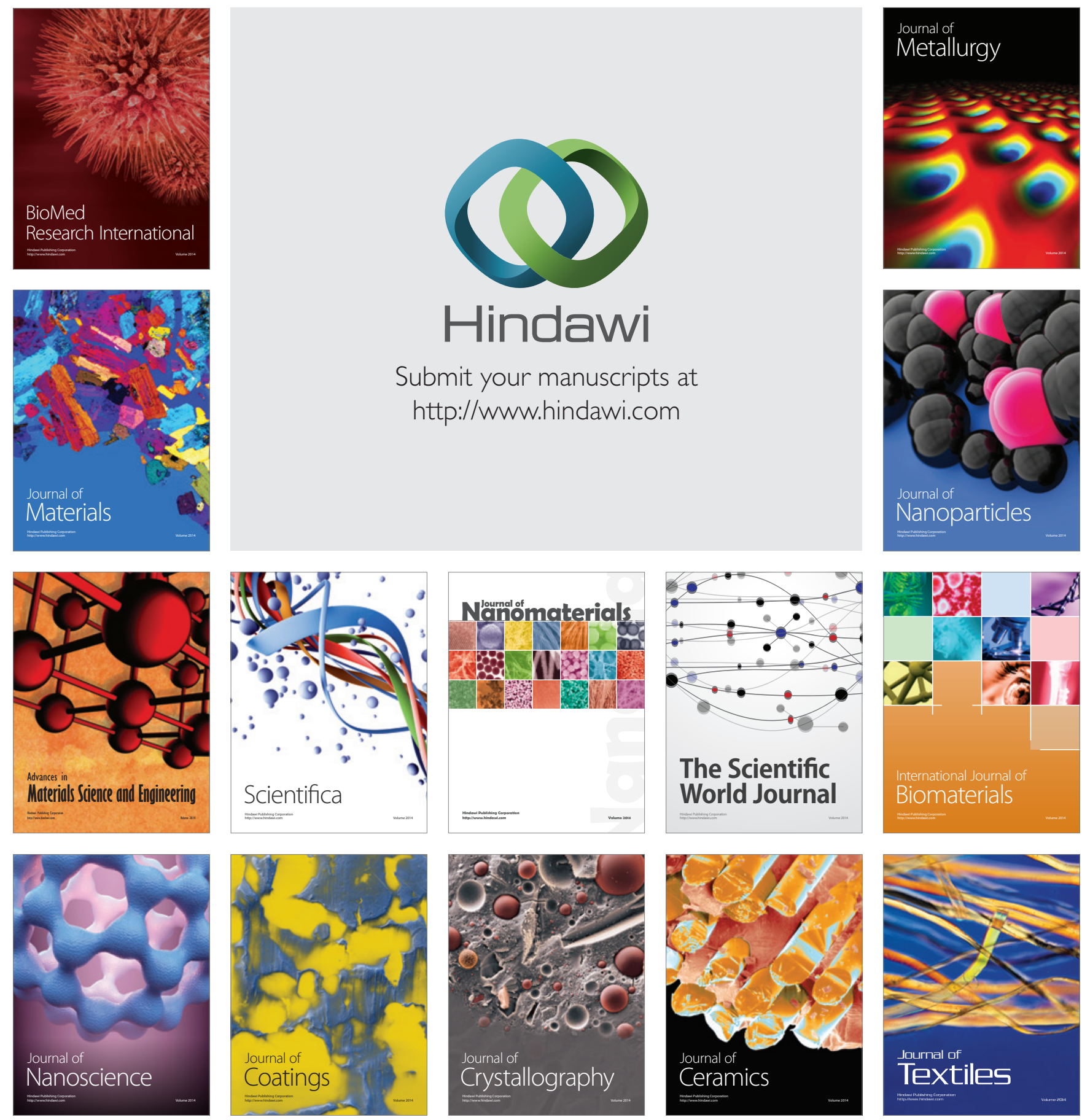